\title{
SYMPOSIUM
}

\section{The impact of HIV epidemic phases on the effectiveness of core group interventions: insights from mathematical models}

\author{
M-C Boily, C Lowndes, M Alary
}

Sex Transm Infect 2002;78(Suppl I):i78-i90

Mathematical models have highlighted the disproportionate contribution of core group transmitters to the spread of sexually transmitted diseases. Because the effectiveness of interventions varies with time, it has been suggested that epidemic phases should be considered in the design of prevention strategies. This study aimed to examine the impact of HIV epidemic phases on the effectiveness of HIV interventions based on gonorrhoea screening and condom use, targeted to core groups. The results are based on a mathematical model of gonorrhoea and HIV transmission in a relatively slow spreading HIV epidemic using Cotonou (Benin) as an example. For epidemics with a low reproductive potential modest core group interventions can significantly reduce HIV incidence and prevalence. As the epidemic matures, effective interventions should also incorporate core and non-core populations. For epidemics with a high reproductive potential, core group interventions are necessary but not sufficient to have a rapid and large scale impact. A more general population approach is also needed early in the epidemic. Epidemic phases are also important in the evaluation of prevention strategies.

See end of article for authors' affiliations

Correspondence to: Dr Marie-Claude Boily, Centers for Disease Control and Prevention, National Center for HIV, STD, and TB Prevention, Division of Sexually Transmitted Diseases Prevention,

Statistics and Data

Management Branch,

Mailstop E63, 1600

Clifton Road, Atlanta, GA

30333, USA;

mcboily@cdc.gov

Accepted

30 November 2001
M thematical models of disease transmission have highlighted the importance of core group transmitters on the establishment and persistence of sexually transmitted dieases (STD). ${ }^{12}$ "Establishment" refers to the initial exponential spread of an infectious agent when introduced in a wholly susceptible population. "Persistence" relates to the long term maintenance of the infection at its equilibrium prevalence. The "core group" is the set of individuals who have a level of risk behaviour sufficient to generate viable chains of transmission in a population and in absence of which the infection would die out. ${ }^{12}$ Because core group individuals contribute disproportionately to disease transmission they are very important to target for effective STD prevention..$^{3-5}$ The effectiveness of core group interventions may be more obvious for bacterial STD with a short reproductive cycle because these react quickly to changes. ${ }^{67}$ For an infection with a long incubation period like HIV, in settings where the initial spread is fast or where prevalence is high, their impact may seem more doubtful. The effectiveness of interventions has been shown to vary with time. $^{6-10}$ It has also been suggested that the epidemic phases that influence transmission should be taken into account in the design of prevention strategies. ${ }^{11}$

In this paper, we study the impact of HIV epidemic phases on the effectiveness of prevention strategies based on gonorrhoea screening and condom use, targeted to high risk groups. We explain why core group interventions are important throughout the course of the HIV epidemic, what magnitude of impact should be expected, and over what time scale. The results are based on a mathematical model of gonorrhoea and HIV transmission in a relatively slow spreading HIV epidemic. Cotonou (Benin) was chosen as an example because 20 years after the postulated introduction of HIV, ${ }^{12-14}$ the epidemic is still characterised by low rates of HIV in both the female and male general population. In the high risk population, such as commercial sex workers and their clients, while the rate of spread was very rapid it has levelled to around $50-55 \%$ (16\% in boyfriends; $8 \%$ in clients), and even seems to be decreasing in the sex workers since 1998-9. ${ }^{14}$ The studies by Alary et al, ${ }^{15}$ Lowndes et al, ${ }^{14}{ }^{16}$ and the study group on heterogeneity of HIV epidemics in African cities ${ }^{13}{ }^{17}$ provide valuable data for investigating the impact of prevention efforts targeted to commercial sex workers and their clients in low and high HIV endemic prevalence epidemics. Our analysis examines the likely effectiveness of past interventions in Cotonou and how it could be improved. The interventions are also evaluated in the context of a high HIV prevalence. Our results show that the epidemic phases are not only important in designing intervention strategies but also in their evaluation.

At the beginning of the HIV epidemic, predictions derived from mathematical models of disease transmission were considered merely speculative and imprecise, because this type of analysis was wrongly seen as a projection tool rather than as an analytical tool. As the data on HIV have accumulated in recent years, models have gained in respect and popularity. ${ }^{18}$ It became clear that dynamic models can, in combination with data, reach their full potential and usefulness, and play many roles in helping us to understand the transmission mechanisms underlying the data. As models have increased in complexity to address public health questions, simple models are still required to test theories and understand fundamental questions. 


\section{METHODS Model}

The analysis is based on a deterministic model that describes the course of HIV and gonorrhoea transmission and incorporates demographic, biological, and behavioural parameters. The model represents an open population of heterosexually active individuals. Each sex is divided into a low sexual activity class (low risk) and high sexual activity class (for example, commercial sex workers and frequent clients of sex workers). The model integrates a structure for the sexual mixing pattern that can range from assortative to disassortative. It also includes a factor to control the renewal of the prostitute population as AIDS spreads into the population.

The natural history of the STD is divided into two states: STD susceptible/non-infected and infected/infectious. STD positive individuals remain infectious for an average duration, after which they recover and become susceptible again. The natural course of HIV infection is divided into five states: HIV susceptible; HIV infected in phase 1; HIV infected in phase 2; HIV infected in phase 3; and full blown AIDS. HIV individuals progress unidirectionally from one state to another (that is, there is no recovery), at a rate that is the inverse of the time spent in each compartment.

Immediately after infection, HIV positive individuals are in phase 1 for a few months, during which they are highly infectious. They progress and remain in phase 2 for many years, during which they are relatively less infectious. Once in phase 3 , they remain for a few years with an infectivity level in between that of phase 1 and phase 2. Full blown AIDS individuals have a shorter life expectancy because of their clinical condition and are assumed to not be sexually active. It is further assumed that HIV has no direct impact on the course of the STD. However, the STD can favour HIV transmission by increasing the HIV susceptibility of an $\mathrm{STD}^{+} / \mathrm{HIV}^{-}$individual if exposed to an $\mathrm{HIV}^{+}$partner, and the HIV infectivity of $\mathrm{STD}^{+} / \mathrm{HIV}^{+}$individuals for their $\mathrm{STD}^{-} / \mathrm{HIV}^{-}$partners. In both cases, the relative increase in the instantaneous risk of HIV infection owing to the STD is designated $\mathrm{RR}_{\text {HIV/STD }}$. An individual can therefore be susceptible to both STD and HIV, and be infected with one or the other, or with both. The mathematical formulation and parameter values of the general model are presented in the appendix and in table 1 , respectively.

\section{Prevention strategies simulated}

Prevention strategies under the SIDA $1 / 2$ project

It has been postulated that the epidemic in Cotonou has been somewhat contained because of male circumcision $(97 \%$ of males are circumcised ${ }^{13}$ ), the sexual activity structure, and to a certain extent by the preventive measures that have been implemented from 1992 onwards by the SIDAl/2 project. ${ }^{14}{ }^{45}$ Therefore the first intervention modelled is the one that is currently in place ( since 1992). The epidemiological data are described and discussed more thoroughly in the paper by Lowndes et al in this issue. ${ }^{14}$

In short, the SIDAl $/ 2$ project or West African AIDS project phases 1 and 2, funded by CIDA (Canadian International Development Agency), is ongoing since 1992. SIDAl/2 works closely with the Programme nationale de lutte contre le SIDA (PNLS) and focuses its activities in Cotonou, where it is the major intervenor with Population Service International (PSI), which carries out social marketing of condoms. Principal activities include training in and supervision of primary health care facilities in syndromic STD management, in conjunction with activities implemented by local nongovernmental organisations (NGO) and directed at specific risk groups (commercial sex workers, male clients, truck drivers, military, prisoners, and so on). These encourage consultation for sexually transmitted diseases at SIDA2 supported health facilities, as well as promoting safer sexual behaviour, including condom use.
A major focus of the SIDA2 project in Cotonou is on STD management and HIV prevention in commercial sex workers. SIDA2 supported free clinical STD management and active STD screening (based on a clinical algorithm), as well as voluntary HIV counselling/testing and free condom provision, are available at a confidential clinic for commercial sex workers in Cotonou. Clinic outreach workers visit all known commercial sex workers in Cotonou at regular intervals to carry out prevention activities and to encourage them to come to the clinic for regular medical check ups, whether or not they have obvious symptoms of STD. ${ }^{14-16}$

\section{STD management/treatment}

Between April 1996 and December 1999, 2957 cases of STD were diagnosed and treated in commercial sex workers. ${ }^{14}$ Given the specificity of the clinical algorithm, a maximum of 1000 of these was assumed to be true gonorrhoea cases. ${ }^{46}$ In our model this corresponds to a $50 \%$ level of screening (that is, coverage: $C_{22} \%=50 \%$ ) of commercial sex workers once a year (annual frequency: $F_{22}=1$ ) starting in 1993. As a result, 940 gonorrhoea cases are treated in our model between 1996 and 1999.

\section{Condom use approach}

As stated in table 1, we assumed a $50 \%$ baseline level of condom use in all relationships between men and commercial sex workers $\left(\right.$ Cond $_{212} \%(1980)=$ Cond $_{222} \%(1980)=$ Cond $_{121} \%(1980)=$ Cond $\left._{122} \%(1980)=50 \%\right)$. This is not counted as part of the interventions. Then, from 1993 onward we assumed that, as part of the SIDAl/2 intervention in 1993 there is an increase in condom use between commercial sex workers and clients over the baseline value. Between 1993 to 1999, reported condom use by commercial sex workers oscillated between $58 \%$ and $75 \%,{ }^{13-15}{ }^{17}$ an increase of $16 \%$ to $55 \%$ over our baseline value of $50 \%$. For the SIDAl $/ 2$ intervention, we used an extra $20 \%$ condom use $(50 \%+50 \% \times 20 \%=60 \%)$ in contacts between commercial sex workers and frequent clients only (high risk) from 1993 onward $\left(\right.$ Cond $_{222} \%(1993)=20 \%$, Cond $212(1993)=$ $0)$. Because the frequency of condom use by clients with more regular partners is very low in comparison with commercial sex workers, we ignored it. ${ }^{14}$

\section{Different interventions}

The different core group interventions focus mainly on the use of condoms between commercial sex workers and frequent clients (interventions B, C1, S2, C2, and CS) and the screening of gonorrhoea among commercial sex workers and frequent clients (interventions B, E, S2, and CS). A more general population approach (C4) also targets relationships between frequent clients and low risk women. For each strategy, the coverage, frequency, and time of introduction are varied. The mathematical formulation and parameter values of the intervention strategies are presented in the appendix and in table 2.

\section{Evaluation}

The effectiveness is measured by the fraction of new HIV infections prevented over a period of time $\mathbf{d t}$ following the introduction of intervention, $s$, at time t. The prevented fractions $\left(\mathrm{PF}_{\mathrm{t}}(\mathbf{d t})\right)$ is defined as:

$$
P F_{t}(\mathbf{d t})=\left[I D_{0}(t, t+d t)-I D_{s}(t, t+d t)\right] / I D_{0}(t, t+d t)
$$

Where $\operatorname{ID}_{0}(t, t+\mathbf{d t})$ is the incidence density of HIV from $t$ to $t+\mathbf{d t}$ in absence of intervention, and $\operatorname{ID}_{s}(t, t+\mathbf{d t})$ is the incidence density of HIV from to $t+\mathbf{d t}$ in presence of the intervention $s . \mathrm{PF}_{\mathrm{t}}(\mathbf{d t})$ is measured over a 1,10 , or 20 year period when the intervention is introduced at different times 
Table 1 Parameter values for the Cotonou scenario

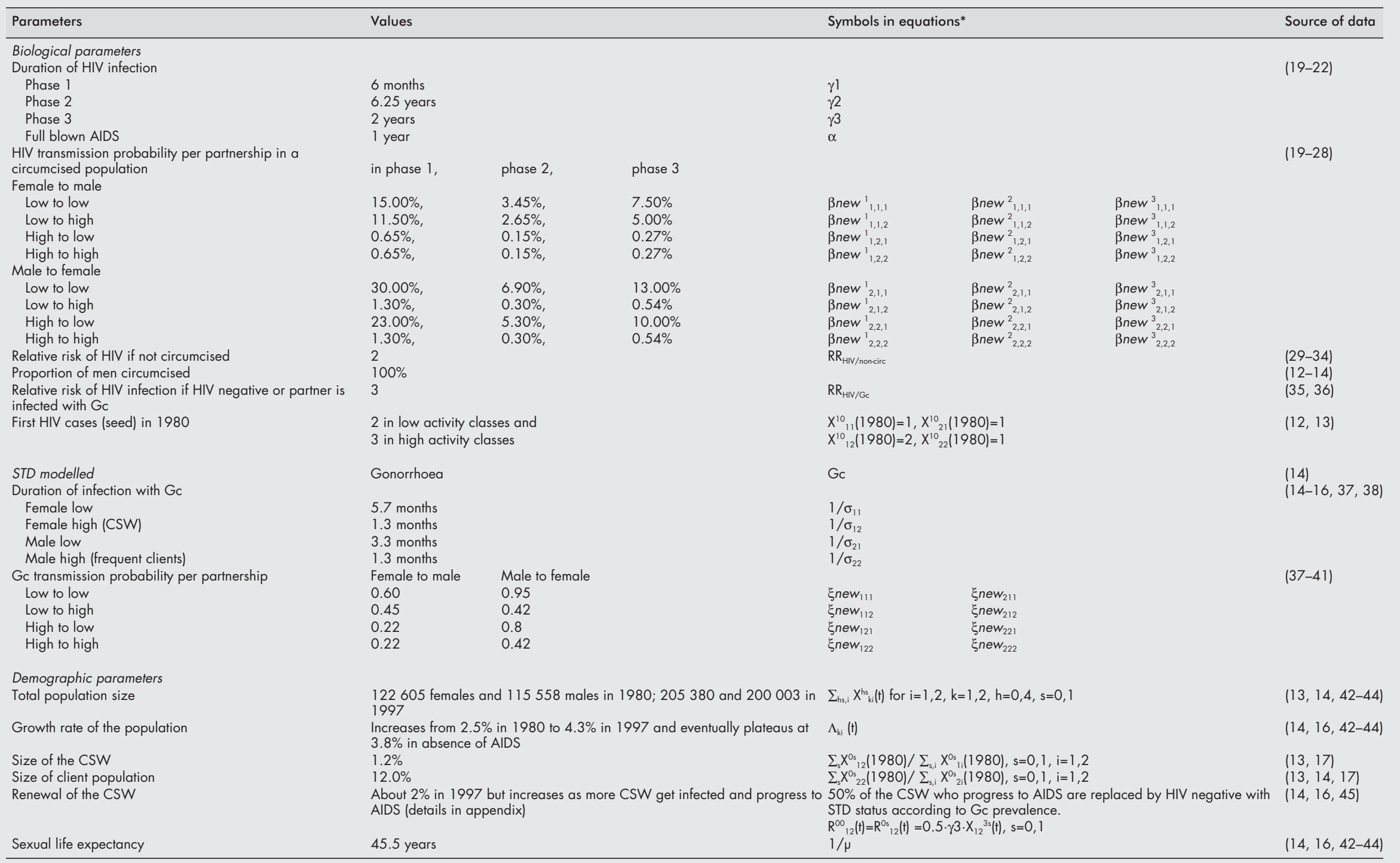




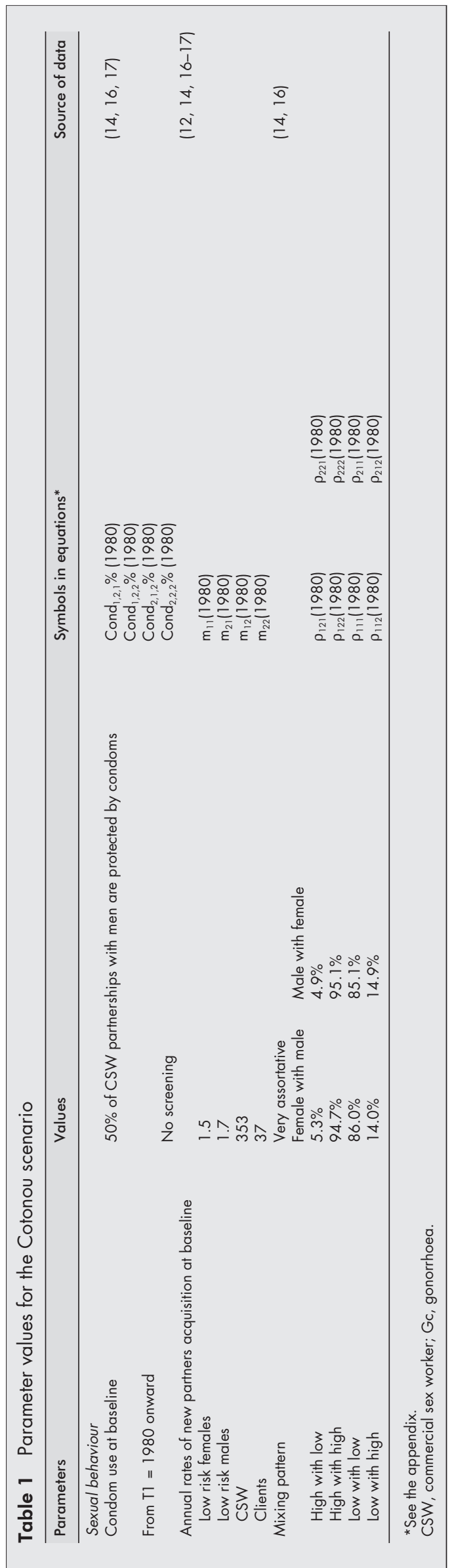

during the course of the epidemic. Because the prevented fraction is based on incidence, it measures the immediate effect of the intervention. As most surveillance data in developing countries come from serial cross sectional studies, we also look at the impact of interventions on HIV prevalence trends. Being based on a dynamic model, the evaluation accounts for the direct and indirect effects of the reduction in susceptibility and infectivity provided by the intervention.

\section{RESULTS}

\section{Low HIV prevalence scenario: Cotonou}

Predicted HIV and gonorrhoea prevalence trends obtained with the Cotonou scenario are shown in fig 1 , panels A-D, for the general population and the high risk groups. The points represent field estimates of comparable risk groups..$^{13}$ The model predictions are consistent with the observed data for both HIV and gonorrhoea infections in the general and high risk populations. The predicted HIV curves in the general population fall between point prevalence estimates of the four cities study $(\mathbf{\Delta} \mathrm{l} \diamond \mathrm{l})$ and estimates from antenatal clinics (lower series of $\diamond$ ). ${ }^{12-14} 17$ The simulated HIV prevalence increases from 1985 onward and peaks around $2.6 \%$ in 2000 and 1997 in the female and male population. The recent prevalence estimates from the four cities in $1999^{13}$ are (mean (SD)) $3.3(1.2) \%$ and $3.4(1.1) \%$ in the female and male population, respectively. This is higher than our model predictions for 1999 and the 2.5 (1.3)\% estimate from antenatal clinics, which may underestimate the true prevalence in women. ${ }^{47} \mathrm{It}$ is therefore unclear whether HIV will continue to rise in the general population and, if so, for how long a period of time.

The maximum prevalence for the general male and female populations is reached two and five years, respectively, after the peak in high risk groups. Note the small difference in HIV prevalence between female and male subjects, despite a twofold discrepancy between male to female and female to male transmission probabilities. The levelling and decrease of HIV in commercial sex workers after 1993 is apparent, but the model overestimates the point prevalence estimate of 40.7 $(4.0) \%$ in $1999 .^{14} 1517$ This may be because we have not accounted for the possible increase in condom use in $1996^{14}$ and it leads to more conservative estimates of condom use in SIDAl/2 intervention. Gonorrhoea prevalence is greater at onset but the decline with time after 1993 agrees well with observed trends (fig 1, panels C and D). Under this set of assumptions, the basic reproductive rate of $\mathrm{HIV}, \mathrm{Ro}_{\text {HIV/Gc- }}(\mathrm{Go}$, gonorrhoea), is less than 1 in the absence of gonorrhoea or if $\mathrm{RR}_{\text {HIV/Gc+ }}=1$. The basic reproductive rate refers to the ability of the infection to become established in a population. $\mathrm{Ro}_{\text {HIV }}$ is greater than 1 if an index HIV case produces on average more than one new case of infection following its introduction in an entirely susceptible population. Where $\mathrm{Ro}_{\text {HIV/Gc- }}$ is less than $\mathrm{l}$, HIV cannot establish or persist in the absence of gonorrhoea.

The model features the important characteristics of the HIV epidemic in Cotonou, namely the explosive initial growth of the HIV epidemic in commercial sex workers, the levelling and then decrease in HIV prevalence among sex workers, the more contained prevalence in clients, the low overall HIV prevalence in the general population 20 years after the beginning of the epidemic, the equal male to female HIV prevalence ratio, and the decline in gonorrhoea rates with time. This scenario can therefore be used as a starting point to study the effectiveness of interventions in a low prevalence epidemic.

Effectiveness of the different interventions Low HIV prevalence scenario (Cotonou)

First, we investigated the impact of SIDAl/2 intervention in Cotonou. Figure 2, panels A-D, illustrates HIV prevalence with time in the overall female and male (panels A and C) and the commercial sex worker and client populations (panels B and D). 
Table 2 Definition of the different core group interventions simulated at time T2

\begin{tabular}{|c|c|c|}
\hline Interventions & Symbols in equations* & Definitions \\
\hline B: Current (SIDA l/2 project): & 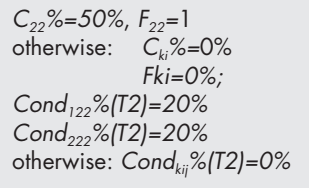 & $\begin{array}{l}50 \% \text { CSW screened for Gc every year } \\
20 \% \text { increase in condom use in relationships between CSW and frequent clients. Net } \\
\text { increase from } 50 \% \text { at baseline to } 60 \% \text { after the intervention }\end{array}$ \\
\hline C1: Condom only: & $\begin{array}{l}C_{k i} \%=0 \% \\
\text { Fki }=0 \% \text { for all } k, i \\
\text { Cond }_{122} \%(\mathrm{~T} 2)=20 \% \\
\text { Cond }_{222} \%(\mathrm{~T} 2)=20 \% \\
\text { otherwise: } \text { Cond }_{k i j} \%(\mathrm{~T} 2)=0 \%\end{array}$ & $\begin{array}{l}\text { No screening } \\
20 \% \text { increase in condom use in relationships between CSW and frequent clients. Net } \\
\text { increase from } 50 \% \text { at baseline to } 60 \% \text { after the intervention }\end{array}$ \\
\hline E: Gc eradication & $R R_{H I V / G c}=1$ when $t \geqslant T 2$ & Gc totally eliminated from the population \\
\hline S2: Screening CSW + Clients & $\begin{array}{l}C_{22} \%=100 \%, F_{22}=6 \\
C_{12} \%=100 \%, F_{12}=12 \\
\text { otherwise: } \quad C_{k i} \%=0 \% \\
F k i=0 \%\end{array}$ & Screening $100 \%$ frequent male clients every 2 months $+100 \%$ CSW every month \\
\hline C2: Condom only & $\begin{array}{l}\text { Cond }_{122} \%(\mathrm{~T} 2)=20 \% \\
\text { Cond }_{222} \%(\mathrm{~T} 2)=20 \% \\
\text { otherwise: } \text { Cond }_{k i j} \%(\mathrm{~T} 2)=0 \%\end{array}$ & $\begin{array}{l}50 \% \text { increase in condom use in relationships between CSW and frequent clients. Net } \\
\text { increase from } 50 \% \text { at baseline to } 75 \% \text { after the intervention }\end{array}$ \\
\hline C4: Condom only & $\begin{array}{l}\text { Cond }_{122} \%(\mathrm{~T} 2)=20 \% \\
\text { Cond }_{222} \%(\mathrm{~T} 2)=20 \% \\
\text { Cond }_{221} \%(\mathrm{~T} 2)=30 \% \\
\text { Cond }_{112} \%(\mathrm{~T} 2)=30 \% \\
\text { otherwise: } \text { Cond } \\
\text { kij } \%(\mathrm{~T} 2)=0 \%\end{array}$ & $\begin{array}{l}\mathrm{C} 1 \\
+30 \% \text { condom use between clients and low risk females }\end{array}$ \\
\hline CS: Screening +Condom: & $\begin{array}{l}\text { Cond }_{122} \%(\mathrm{~T} 2)=20 \% \\
\text { Cond }_{222} \%(\mathrm{~T} 2)=20 \% \\
\text { otherwise: } \text { Cond }_{\mathrm{kij}} \%(\mathrm{~T} 2)=0 \% \text {; } \\
\mathrm{C}_{12} \%=100 \%, \mathrm{~F}_{12}=6 \\
\text { otherwise: } \quad \mathrm{C}_{\mathrm{k}} \%=0 \% \\
\quad \mathrm{Fki}=0 \%\end{array}$ & $\begin{array}{l}\text { C1 } \\
+ \text { Screening of CSW every } 2 \text { months }\end{array}$ \\
\hline
\end{tabular}

The intervention is introduced at time $\mathrm{T} 2=1985,1990$, 1993, 1996, 2005 compared with no intervention (no intervention except the baseline condom use). The fractions of new HIV cases prevented by the intervention after one year $\left(\mathrm{PF}_{1993}(1)\right)$ and after 20 years $\left(\mathrm{PF}_{1993}(20)\right)$ are also shown on the graphs. Under our current assumptions, the model predicts that the current SIDAl/2 intervention, introduced in Cotonou in 1993, may have helped to limit the general HIV epidemic to a prevalence level of around $2.6 \%$ in the general female population, compared with the possible maximum of nearly $5 \%$ without the intervention. This is because of the effectiveness of the intervention in commercial sex workers.

The SIDAl/2 intervention introduced in 1993 may overall have prevented $21 \%$ of HIV infections in women and 33\% in men over a period of one year, and may prevent $48 \%$ of them in women and $51 \%$ of them in men if sustained for 20 years. In commercial sex workers, the corresponding prevented fractions are higher, at $45 \%$ and $71 \%$ over a period of one year and 20 years, respectively. The fraction of new HIV infections prevented decreases with the time of introduction, particularly for the general population and less so for commercial sex workers and clients. This is because commercial sex workers and clients are protected by the intervention through a direct reduction in susceptibility, whereas the remainder of the population is mostly protected indirectly through a reduction in exposure to HIV (herd immunity).

Note that all prevalence curves (and incidence curves; not shown) eventually converge to the same equilibrium (long term prevalence) independently of the time of introduction of the intervention, even if the prevented fraction is smaller with late introduction. Despite the effectiveness of the SIDAl/2 intervention, no longitudinal decline (but a slower rise) in overall HIV prevalence is observed following an early introduction unless the epidemic is at a more mature stage (late introduction), a sign that it approaches its peak or equilibrium (for example, in commercial sex workers). The occurrence of the peak prevalence and the time to reach the new equilibrium prevalence vary according to the time of introduction of the intervention. Early intervention is advantageous not only because it reduces morbidity and mortality but also because it limits the demographic and economic impact of the epidemic.

Table 3 presents the fraction of new infections prevented by the other interventions introduced in 1985, 1993, and for the year 2005, and evaluated over one year and 10 year periods in the low risk, high risk, and overall female and male population. In the short term the apparent effectiveness can be unimpressive, with a $\mathrm{PF}_{\mathrm{t}}(1)$ ranging from $33 \%$ to $74 \%$ when interventions are introduced in 1985 compared with $9 \%$ to $37 \%$ when delayed to the year 2005 . The picture is better over a longer period of evaluation. We note that most of the effectiveness of SIDAl/2 intervention (B) is attributable to the use of condoms $(\mathrm{Cl})$. Clearly the screening intensity in Cotonou is inadequate. Why is screening not more efficient, given that HIV cannot establish without the presence of gonorrhoea?

Intervention $\mathrm{E}$ (gonorrhoea eradication) gives the maximum potential of gonorrhoea based strategies over a one year and a 10 year period. When introduced early (in 1985) the payoff is excellent in all risk groups with overall female (male) $\mathrm{PF}_{1985}(1)=65 \%(75 \%)$ and $\mathrm{PF}_{1985}(10)=96 \%(97 \%)$. However, if the eradication is delayed by 20 years, $\mathrm{PF}_{2005}(1)$ and $\mathrm{PF}_{2005}(10)$ plummet to $22 \%(33 \%)$ and $34 \%(41 \%)$ in the overall female (male) population. The eradication of the STD represents the maximum effectiveness, which may never be achievable even by mass treatment. ${ }^{6}$ 

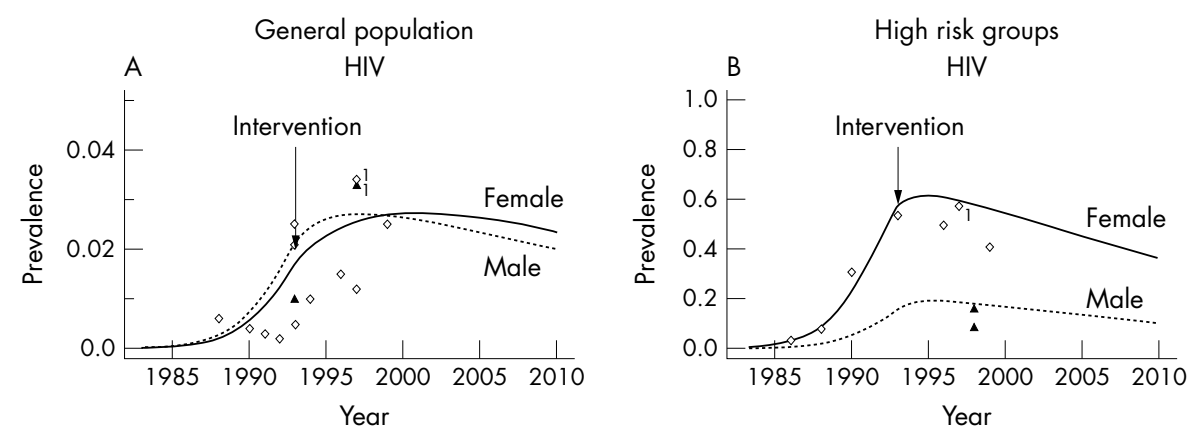

Figure 1 HIV prevalence as a function of time, based on the parameter set for Cotonou. This includes the current SIDA $1 / 2$ intervention introduced in 1993. Panels $\mathrm{A}$ and $\mathrm{C}$ represent HIV and gonorrhoea $(G c)$, respectively, in the overall female and male populations. Panels B and D represent female and male high risk groups, that is, commercial sex workers and their clients. The points indicate the corresponding field estimates for female subjects and male subjects. Estimates are from
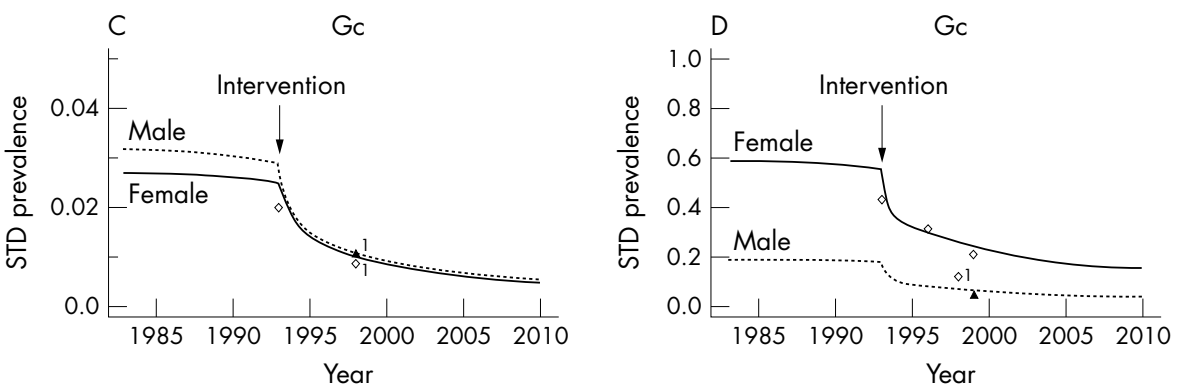
the $\mathrm{PHLS}$ and SIDAl $/ 2$ projects in Cotonou ${ }^{14} 16$ and the four cities study. ${ }^{12} 1317$ STD, sexually transmitted disease.

Thus two interventions with different gonorrhoea screening intensities have been evaluated. In intervention $\mathrm{CS}$, the screening component of SIDA $1 / 2$ is extended to the whole commercial sex worker population every two months instead of being limited to $50 \%$ of sex workers once a year. The maximum $P F(1)$ reaches $44 \%$ and $54 \%$ in female and male subjects, respectively, when introduced in 1985, compared with 13\% and $25 \%$ when introduced in 2005 . The overall prevented fraction over one year is about two thirds that of gonorrhoea eradication, independently of the time of introduction. The difference in effectiveness between intervention CS and gonorrhoea eradication (E) is smaller over the 10 year period.

A similar performance is obtained based solely on gonorrhoea screening (without an increase in baseline condom use) if the commercial sex worker community is screened every month and the male clients of sex workers every 6 months (S2). These results illustrate the screening efforts required to produce rapid benefits on HIV. The intensity required may be difficult to realise and to sustain over long enough periods of time, as it involves screening more than 2000 commercial sex workers and more than 20000 men at least every two months for many years. Interventions based solely on STD treatment may not be realistic for developing countries.

Although this requires a detailed cost-effectiveness analysis, a more realistic approach may be a mixture of interventions combining both condom use and frequent STD screening of commercial sex workers (for example, intervention CS). Turning to condom use only, intervention C2, which implies a $50 \%$ increase in baseline condom use (that is, from $50 \%$ to $75 \%$ ), is always better than the previous interventions except for gonorrhoea eradication after one year of evaluation. The prevented fraction over one year decreases from $60 \%$ in 1985 to $19 \%$ in 2005 for women and from $64 \%$ to $37 \%$ for men.
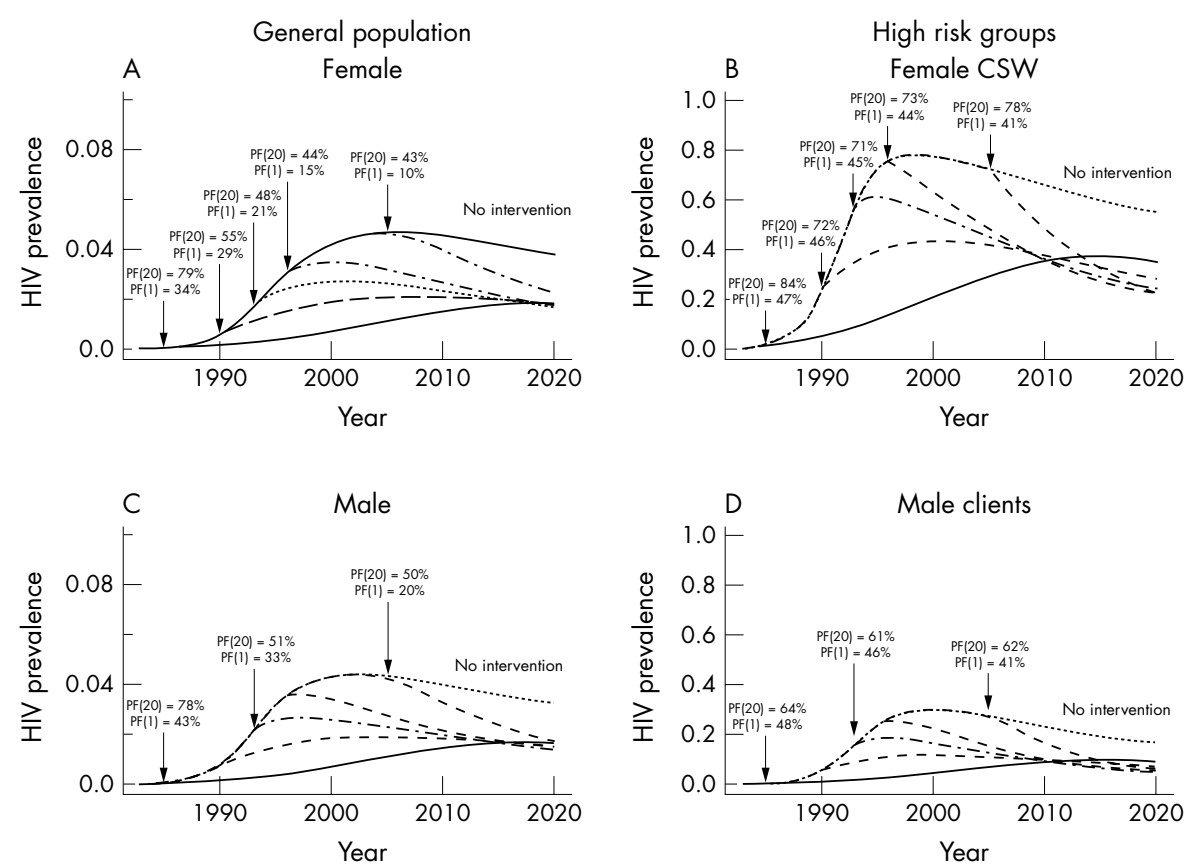

Figure 2 Time trends in HIV prevalence when the current intervention $(B)$ is introduced at different times during the course of the epidemic in the overall $(A, C)$ and high risk $(B, D)$ female and male populations. The prevented fractions (PF) calculated over the next 1 and 20 years following the introduction of the intervention are also given. 
Table 3 Prevented fraction (PF) of HIV after the introduction of the different intervention strategies in the low prevalence scenario (Cotonou) in 1985, 1993, and 2005

\begin{tabular}{|c|c|c|c|c|c|c|c|c|c|}
\hline \multirow[b]{3}{*}{ Interventions } & \multicolumn{9}{|c|}{$\begin{array}{l}\text { Start of intervention; } \\
\text { PF (time interval (years)) (\%) }\end{array}$} \\
\hline & \multicolumn{3}{|c|}{$\begin{array}{l}\text { 1985: } \\
\text { PF (1) } \\
\text { PF(10) } \\
\text { Risk groups* }\end{array}$} & \multicolumn{3}{|c|}{$\begin{array}{l}\text { 1993: } \\
\text { PF(1) } \\
\text { PF(10) } \\
\text { Risk groups* }\end{array}$} & \multicolumn{3}{|c|}{$\begin{array}{l}\text { 2005: } \\
\text { PF(1) } \\
\text { PF(10) } \\
\text { Risk groups* }\end{array}$} \\
\hline & Low & High & Overall & Low & High & Overall & Low & High & Overall \\
\hline \multicolumn{10}{|l|}{ B: SIDAI/2 } \\
\hline \multirow[t]{2}{*}{ Female } & 22 & 47 & 34 & 15 & 45 & 21 & 6 & 41 & 10 \\
\hline & 85 & 88 & 85 & 42 & 68 & 42 & 27 & 68 & 30 \\
\hline \multirow[t]{2}{*}{ Male } & 15 & 46 & 43 & 8 & 40 & 33 & 2 & 36 & 20 \\
\hline & 83 & 88 & 87 & 36 & 58 & 47 & 18 & 61 & 38 \\
\hline \multicolumn{10}{|c|}{ C1: Extra $20 \%$ condom use between CSW and clients } \\
\hline \multirow[t]{2}{*}{ Female } & 21 & 45 & 33 & 14 & 44 & 20 & 6 & 40 & 9 \\
\hline & 84 & 86 & 83 & 40 & 65 & 39 & 25 & 66 & 28 \\
\hline \multirow{2}{*}{ Male } & 14 & 44 & 41 & 7 & 38 & 32 & 2 & 34 & 19 \\
\hline & 81 & 86 & 85 & 33 & 55 & 45 & 17 & 59 & 37 \\
\hline \multicolumn{10}{|c|}{ E: Gc eradication } \\
\hline \multirow[t]{2}{*}{ Female } & 51 & 78 & 65 & 40 & 75 & 47 & 17 & 59 & 22 \\
\hline & 96 & 96 & 96 & 62 & 84 & 63 & 31 & 68 & 34 \\
\hline \multirow[t]{2}{*}{ Male } & 43 & 77 & 74 & 29 & 71 & 63 & 9 & 55 & 33 \\
\hline & 94 & 98 & 97 & 56 & 78 & 68 & 22 & 62 & 41 \\
\hline \multicolumn{10}{|c|}{ S2: Screening CSW every month + clients every 2 months } \\
\hline \multirow[t]{2}{*}{ Female } & 32 & 57 & 45 & 24 & 55 & 30 & 11 & 46 & 14 \\
\hline & 95 & 95 & 95 & 58 & 82 & 58 & 29 & 67 & 32 \\
\hline \multirow[t]{2}{*}{ Male } & 25 & 55 & 52 & 15 & 48 & 42 & 5 & 39 & 23 \\
\hline & 93 & 97 & 96 & 52 & 74 & 64 & 21 & 60 & 40 \\
\hline \multicolumn{10}{|c|}{ C2: Extra $50 \%$ condom use between CSW and clients } \\
\hline \multirow[t]{2}{*}{ Female } & 41 & 80 & 60 & 29 & 79 & 41 & 12 & 73 & 19 \\
\hline & 97 & 99 & 97 & 67 & 93 & 70 & 36 & 87 & 41 \\
\hline \multirow[t]{2}{*}{ Male } & 29 & 79 & 74 & 16 & 74 & 63 & 5 & 66 & 37 \\
\hline & 95 & 99 & 98 & 58 & 89 & 78 & 24 & 81 & 52 \\
\hline \multicolumn{10}{|c|}{$\mathrm{C} 4: \mathrm{C} 1+$ extra $30 \%$ condom use between clients and low risk females } \\
\hline \multirow[t]{2}{*}{ Female } & 43 & 45 & 44 & 37 & 44 & 37 & 24 & 40 & 25 \\
\hline & 89 & 87 & 86 & 56 & 66 & 53 & 39 & 67 & 41 \\
\hline \multirow[t]{2}{*}{ Male } & 21 & 44 & 42 & 13 & 39 & 34 & 5 & 37 & 22 \\
\hline & 85 & 87 & 86 & 46 & 57 & 50 & 25 & 61 & 42 \\
\hline \multicolumn{10}{|c|}{$\mathrm{CS}$ : $\mathrm{C} 1+$ screening of CSW every 2 months } \\
\hline \multirow[t]{2}{*}{ Female } & 29 & 59 & 44 & 20 & 57 & 28 & 9 & 52 & 13 \\
\hline & 94 & 97 & 97 & 58 & 84 & 59 & 31 & 75 & 35 \\
\hline Male & 22 & 57 & 54 & 12 & 51 & 43 & 4 & 45 & 25 \\
\hline & 92 & 97 & 96 & 50 & 77 & 65 & 21 & 68 & 44 \\
\hline
\end{tabular}

Because of the decreasing effectiveness of core group interventions with time, we looked at the effect of a more general population approach. Intervention C4 is coupled with a $20 \%$ increase in condom use for relationships between frequent clients and commercial sex workers, and with a 30\% increase for those between frequent clients and low risk partners. When introduced in 1985, it is less effective than the other interventions with the exception of SIDAl/2. Although it tends to favour women, the relative performance of intervention C4 improves compared with the others when introduced at a later stage of the epidemic, when overall HIV prevalence increases. Early in the epidemic (1985 and 1993) the best two interventions are the eradication of gonorrhoea and intervention C2. Later in 2005, interventions C2 and C4 are the best. Typically the relative reduction in incidence (that is, the $\mathrm{PF}_{\mathrm{t}}$ ) is larger (for delayed interventions) or equal (for early interventions) in commercial sex workers than in male clients of commercial sex workers, in low risk women, and in low risk men, reflecting the way the virus spreads in the population. The gap in the fraction prevented between men and women from the low risk group increases when the intervention is delayed, reflecting the larger distance to the primary source of the intervention in low risk males. Because the size of the client population is larger than the size of the commercial sex worker population, the overall prevented fraction is larger for men than for women.

Figure 3, panels A and B, compares change in female and commercial sex worker HIV prevalence over time following the introduction of the interventions in 1993.

The most aggressive interventions induce a faster decline in prevalence in commercial sex workers, compared with a slow rise in the overall population or in the low risk group. Apart from intervention C4 (which is the worst in commercial sex workers and second worst in women overall), the largest decrease in HIV prevalence is obtained with the same intervention in both commercial sex workers and the overall female population. The best intervention, which is the $50 \%$ increase in condom use in relationships between frequent clients and commercial sex workers (C2), reduces the overall female (commercial sex worker) HIV prevalence to less than $1.0 \%(21 \%)$ and $0.5 \%(2.4 \%)$ after 10 and 30 years of sustained efforts. SIDAl/2 (and Cl) is the worst intervention and limits overall female (commercial sex worker) HIV prevalence to $2.7 \%(49 \%)$ and $1.6 \%$ (25\%) after 10 and 30 years, respectively. The corresponding figures for women in the general population and commercial sex workers, without prevention, are $4.6 \%(75 \%)$ and $3.8 \%(54 \%)$ after 10 and 30 years, respectively. Intervention C2 causes $80 \%(80 \%)$ and $73 \%(96 \%)$ reduction in overall female and commercial sex worker prevalences after 

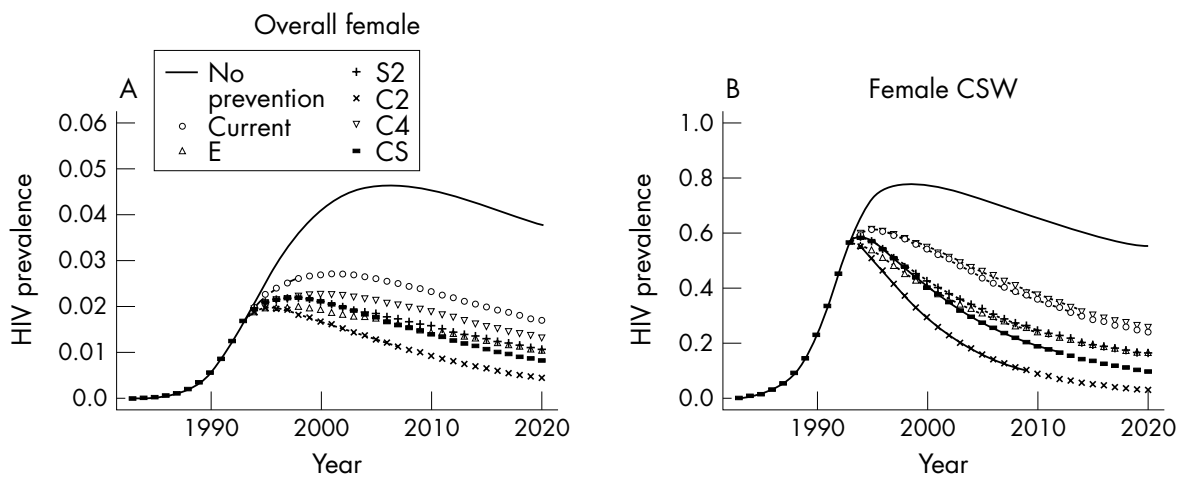

Figure 3 Time trends in HIV prevalence following the introduction in 1993 of various interventions in overall (A) and high risk (B) female populations for the Cotonou scenario. The interventions considered are: none; current (B); gonorrhoea eradication (E); screening of commercial sex workers (CSW) every month and clients every two months (S2); $50 \%$ extra condom use between CSW and regular clients (C2); $20 \%$ extra condom use for relationships between regular clients and CSW, plus 30\% condom use if with low risk women (C4); and 20\% extra condom use between CSW and regular clients, and screening of CSW every two months (CS).

10 (30) years compared with no intervention. SIDAl/2 produces a more than $40 \%$ decline in all risk groups after 10 and 30 years (except in commercial sex workers where the decline is $30 \%$ after 10 years). The reduction in prevalence among commercial sex workers improves over time compared with the general population as the indirect effect of the intervention wanes.

Table 4 Prevented fraction (PF) of HIV after the introduction of the different intervention strategies in the high prevalence scenario in 1993

\begin{tabular}{|c|c|c|c|}
\hline \multirow[b]{2}{*}{ Interventions } & \multicolumn{3}{|c|}{$\begin{array}{l}\text { Start of intervention 1993; } \\
\text { PF (time interval (years)) (\%) } \\
\text { PF (1) } \\
\text { PF (10) }\end{array}$} \\
\hline & $\begin{array}{l}\text { Low risk } \\
\text { group }\end{array}$ & $\begin{array}{l}\text { High risk } \\
\text { group }\end{array}$ & Overall \\
\hline \multicolumn{4}{|l|}{ B: SIDAI/2 } \\
\hline \multirow{2}{*}{ Female } & 9 & 46 & 10 \\
\hline & 24 & 60 & 24 \\
\hline \multirow[t]{2}{*}{ Male } & 5 & 40 & 11 \\
\hline & 19 & 58 & 20 \\
\hline \multicolumn{4}{|c|}{$\mathrm{Cl}$ : Extra $20 \%$ condom use between CSW and clients } \\
\hline \multirow[t]{2}{*}{ Female } & 9 & 44 & 9 \\
\hline & 22 & 56 & 22 \\
\hline \multirow[t]{2}{*}{ Male } & 4 & 24 & 11 \\
\hline & 17 & 36 & 19 \\
\hline \multicolumn{4}{|c|}{ E: Gc eradication } \\
\hline \multirow[t]{2}{*}{ Female } & 30 & 72 & 31 \\
\hline & 38 & 71 & 38 \\
\hline \multirow[t]{2}{*}{ Male } & 19 & 50 & 29 \\
\hline & 32 & 53 & 33 \\
\hline \multicolumn{4}{|c|}{ S2: Screening CSW every month + clients every 2 months } \\
\hline \multirow[t]{2}{*}{ Female } & 19 & 57 & 20 \\
\hline & 36 & 69 & 36 \\
\hline \multirow[t]{2}{*}{ Male } & 11 & 35 & 19 \\
\hline & 30 & 50 & 31 \\
\hline \multicolumn{4}{|c|}{ C2: Extra $50 \%$ condom use between CSW and clients } \\
\hline \multirow[t]{2}{*}{ Female } & 19 & 78 & 20 \\
\hline & 39 & 86 & 40 \\
\hline \multirow[t]{2}{*}{ Male } & 10 & 47 & 23 \\
\hline & 33 & 60 & 36 \\
\hline \multicolumn{4}{|c|}{$\mathrm{C} 4: \mathrm{C} 1+$ extra $30 \%$ condom use between clients and low risk women } \\
\hline \multirow[t]{2}{*}{ Female } & 36 & 47 & 36 \\
\hline & 49 & 63 & 48 \\
\hline \multirow[t]{2}{*}{ Male } & 10 & 40 & 20 \\
\hline & 33 & 57 & 36 \\
\hline \multicolumn{4}{|c|}{$\mathrm{CS}: \mathrm{Cl}+$ screening of CSW every 2 months } \\
\hline \multirow[t]{2}{*}{ Female } & 14 & 59 & 15 \\
\hline & 35 & 75 & 35 \\
\hline \multirow[t]{2}{*}{ Male } & 8 & 33 & 17 \\
\hline & 29 & 52 & 33 \\
\hline
\end{tabular}

CSW, commercial sex worker; Gc, gonorrhoea; high risk group, CSW and frequent clients of CSW.

\section{High prevalence scenario}

In table 4, the interventions are evaluated when introduced in 1993 in a high equilibrium prevalence epidemic. In this set of simulations, we assume that men are not circumcised $\left(\mathrm{RR}_{\mathrm{HIV} / \mathrm{n} \text {-circ }}\right.$ $=2$ ) and the mixing pattern is less assortative than for the Cotonou scenario. The other characteristics are the same (details in the legend of fig 4). The resulting HIV prevalence curves are illustrated in fig 4 .

In this high prevalence setting the best intervention is $\mathrm{C} 4$, which includes condom use between clients and low risk women as well as with commercial sex workers, because it also benefits the women from the low risk group compared with other interventions. In the Cotonou scenario this intervention becomes advantageous only at a later stage of the epidemic. The next best interventions are C2 and E. If sustained for many decades, the overall prevented fraction following gonorrhoea eradication eventually plateaus at $30 \%$ to $40 \%$ in the high prevalence scenario, compared with $100 \%$ in the Cotonou scenario. This occurs because HIV can establish and reach a positive equilibrium of incidence/prevalence even in the absence of gonorrhoea $\left(\mathrm{Ro}_{\text {нाV/Go- }}>1\right)$ in the high prevalence scenario, whereas HIV is slowly driven to extinction in the absence of the STD $\left(\mathrm{Ro}_{\text {HIV/G- }}<1\right)$ in the Cotonou scenario.

Whether this assumption is true or not is important mostly in the long term. The fraction of new cases prevented by the intervention in a high prevalence setting is less for all risk groups compared with the low prevalence scenario. However, at least $20 \%(40 \%)$ and more than $55 \%(65 \%)$ of new infections can be prevented over 10 years in the general population and in commercial sex workers, respectively, in the high prevalence (Cotonou) epidemic. Because changes in HIV prevalence following prevention are slow, the prevented fraction does not capture the full potential of interventions over a short evaluation period, especially if introduced late in the course of the epidemic.

Figure 4, panels A and B, shows the changes in HIV prevalence over time in the overall female population and in commercial sex workers when interventions are introduced in 1993. The decline in HIV prevalence following interventions is more modest than under the low prevalence scenario in both general and high risk populations ( fig 3). The HIV prevalence plateau is reached in the next 10 to 15 years following the intervention, thereby contributing to a reduction in the prevented fraction. The best strategy for commercial sex workers is the $50 \%$ increase in condom use for relationships with frequent clients (C2). This reduces HIV prevalence to $49 \%$ (a $40 \%$ reduction) in commercial sex workers and to $18 \%(33 \%$ reduction) in the overall female population after 10 years, compared with rates of $85 \%$ in commercial sex workers and $27 \%$ in women overall in the absence of intervention. 

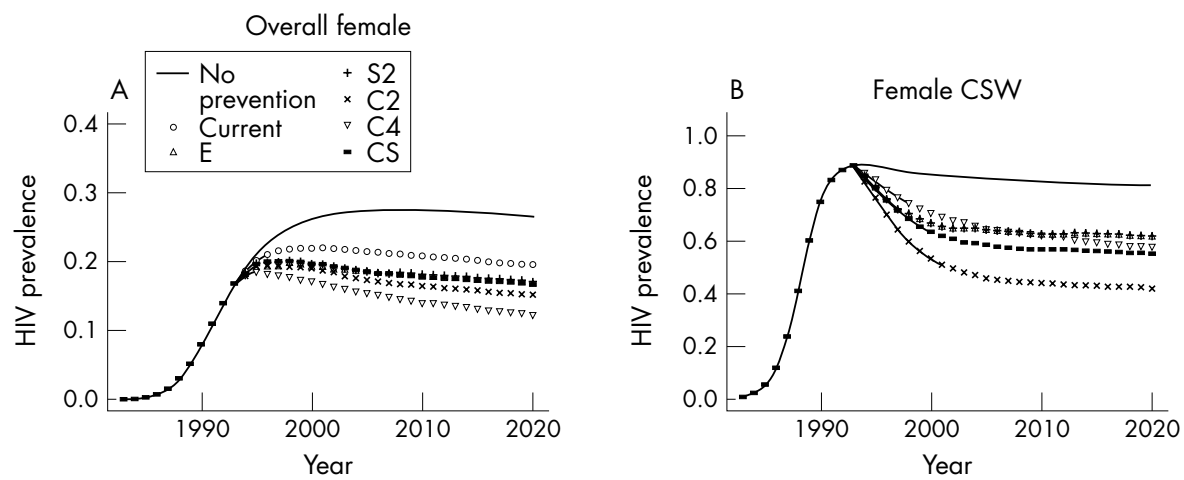

Figure 4 Time trends in HIV prevalence following the introduction in 1993 of various interventions in the overall (A) and high risk (B) female populations for the high prevalence scenario. The interventions were: none; current (B); gonorrhoea eradication (E); screening of commercial sex workers (CSW) every month and clients every two months (S2); $50 \%$ extra condom use between CSW and regular clients (C2); $20 \%$ extra condom use for relationships between regular clients and CSW, plus 30\% condom use if with low risk women (C4); and 20\% extra condom use between CSW and regular clients, and screening of CSW every two months (CS). In this set of simulations, the mixing is less assortative than for Cotonou and assumes the following: 18\% mixing between males clients and low risk women; 19\% mixing between CSW and low risk men; $52 \%$ mixing between low risk women and high risk men; and $47 \%$ mixing between low risk men and low risk women. The population is not circumcised $\left(\mathrm{RR}_{\mathrm{HIV} / \mathrm{non} \text { circ }}=2\right)$. Gonorrhoea prevalence rates within risk groups are adjusted to those of Cotonou by increasing the duration of infection (see the appendix). All other parameters are the same as in table 1.

It is surprising to note that if condoms are used in $100 \%$ of relationships between commercial sex workers and frequent clients, long term HIV prevalence in the sex workers falls to less than $1 \%$, but to only $13 \%$ in the general population (not shown). This is because of the high HIV prevalence in the non-core group and the high transmission potential between members of the core and non-core groups.

The maximum reduction in HIV prevalence in the general female population is now achieved with a more general population intervention (C4, which is the second worst in 1985 and 1993 in Cotonou). It is interesting to contrast the reduction in HIV prevalence after 10 years with the reduction in incidence over 10 years following intervention C4 between scenarios. In commercial sex workers, a $69 \%$ reduction in incidence is followed by a $36 \%$ reduction in HIV prevalence in the high prevalence scenario, compared with a $66 \%$ incidence and a $53 \%$ HIV prevalence reduction in the Cotonou scenario. Overall, incidence and prevalence are reduced by $36 \%$ and $20 \%$, respectively, in the high prevalence scenario, and by $53 \%$ and $30 \%$ in the low prevalence scenario. With SIDAl/2, HIV prevalence in women overall and in commercial sex workers is $22 \%$ and $67 \%$, respectively, after 10 years, resulting in a $20 \%$ reduction in rates.

What is the meaning of these results for the future? If SIDAl/2 is sustained in Cotonou, HIV prevalence will decline further until it plateaus to nearly half its present level, without prevention in the general and commercial sex worker populations-preventing $20-50 \%$ of new infections over 10 years. In the high prevalence scenario, the equilibrium would level around $75 \%$ its value without prevention, preventing $7-24 \%$ of new cases.

\section{DISCUSSION}

\section{Cotonou simulations}

Our results support the idea that the epidemic in Cotonou is self contained, that transmissions from high to lower risk groups will continue to be slow, especially for men compared with women, and that transmission is very low within low risk groups. In our simulations, male circumcision and the type of sexual mixing structure are factors limiting the spread of HIV and producing an equal male to female HIV prevalence ratio. Furthermore, our low intensity intervention introduced in 1993 and targeted to commercial sex workers (SIDAl/2 projects) could explain the observed reversal of HIV prevalence in commercial sex workers, further limiting the spread of HIV in the lower risk groups. The future magnitude of the
HIV epidemic in the general population is difficult to predict because the exact reproductive potential of the infection in the low risk groups is unknown. In the Cotonou scenario, the evolution of the HIV epidemic in the general population echoed that of the higher risk groups within a few years. The spread of HIV in the general population seems to be so intrinsically linked to the epidemic in high risk groups that-unless low risk groups have much higher risk behaviours than currently reported-the overall HIV prevalence is unlikely to increase much further if HIV prevalence continues to decrease in commercial sex workers and clients because of prevention or natural causes. In our model we have made a series of assumptions that may affect our prediction of HIV prevalence in the general populations of Cotonou. They are discussed below.

Impact of AIDS differential mortality on STD rates

Before the introduction of prevention in 1993, the gonorrhoea prevalence predicted by the model decreases slightly from $58 \%$ to $54 \%$ in commercial sex workers, and from $2.7 \%$ and $3.2 \%$ to $2.5 \%$ and $3.0 \%$ in the female and male general population. The overall female and male gonorrhoea rates would have declined further even in absence of intervention. The decline in gonorrhoea over time is not the result of safer sex but of the natural dynamics of the infection owing to differential AIDS mortality, which acts in two ways. It depletes the high risk population and it modifies the sexual structure (mixing pattern, rate of partner acquisition, or any other structural measures of networks) in the population..$^{3548}$ It can also modify the distribution of the clinical manifestations of STD symptoms. ${ }^{50}$ The magnitude of such changes depends on the velocity at which HIV spreads, the behavioural rules guiding the sexual reorganisation of partnerships in response to changes, and the replenishment of the population (especially the high risk population). In our model, if none of the commercial sex workers progressing to full blown AIDS were replaced, the overall female and male gonorrhoea rates in 1998 fall to $1.6 \%$ and $1.9 \%$, respectively. Thus the renewal of commercial sex workers has an impact on STD and HIV rates in both high and low risk groups. In Cotonou, the proportion of Ghanaian and Togolese commercial sex workers, who have the most clients, has decreased between 1993 and 1999. Simultaneously, the fraction of Beninese sex workers, who report the fewest clients, increased over time. ${ }^{145}$ These changes, as well as the decline in gonorrhoea rates and in the number of clients seen by sex workers over time, could be 
explained by individual changes in behaviour, prevention, changes in the commercial sex worker renewal pattern (immigration, emigration, and so on), and the effect of AIDS mortality. These results emphasise the difficulty in determining whether a decrease in STD and changes in sexual behaviour are the result of a successful intervention, of the natural course of the HIV epidemic, or both. In the context of a fast spreading or high prevalence epidemic, it is difficult to imagine that the demographic impact of AIDS has no repercussion at all on sexual activity distributions and thus on STD trends over time. This phenomenon is poorly documented and is likely to have important repercussions in a context where potent antiretroviral treatment may become suddenly and widely available. ${ }^{51}$

\section{Sexual behaviour of low activity groups}

In our model, we have assumed a much higher rate of partner change in the low activity class than currently reported by the general population during a lifetime, ${ }^{13}{ }^{14}{ }^{17}$ otherwise overall HIV prevalence levels remain too low (below 2\%). This suggests some level of underreporting by the low risk group or an underestimation of clandestine prostitution activity. Clandestine prostitutes are believed to be mostly Beninese who live with their family, receive their clients at home, and recruit clients by word of mouth. ${ }^{14}$ By ignoring concurrency, our model may underestimate the risk of the low activity population. ${ }^{52}$ In the four cities study ${ }^{12} 1312 \%$ of never-married men (57\% of the population) reported more than one partnership at the time of the interview. The equivalent figures for women and the fraction of low risk women (men) in relationships with such men (women) are unknown. Concurrency is expected to have a larger impact in the low activity group than among high activity individuals. For someone in a long term relationship or with few sequential partners, the effect of having a regular partner who has concurrent partnerships can be seen, in a simplified manner, as the effect of having sequential new partners. Each time the regular partner returns home, there is a different probability (although not independent of previous status) of carrying the virus, depending on the level of risk of the concurrent partners. Therefore, assuming a larger rate of partner change than reported may compensate for the effect of concurrency on prevalence rates but not precisely.

\section{Nature of relationships between commercial sex workers} and low risk men

We may have underestimated the number of contacts per relationship (only one) between commercial sex workers and low risk men, and overestimated the baseline level of condom use (50\%) during these contacts. If HIV transmission probabilities in partnerships between commercial sex workers and low risk males are five times larger than currently assumed, overall HIV prevalence in 1998 reaches $3.4 \%$ in men and women. In this case, $25 \%$ extra condom use between commercial sex workers and frequent clients has to be assumed during SIDAl/2 intervention to reverse the HIV prevalence trends in commercial sex workers.

\section{Baseline use of condom}

Initially, we assumed a 50\% condom use in all partnerships involving commercial sex workers (for both low and high risk men). If no condoms are used at baseline, HIV prevalence peaks to $95 \%$ within eight years in commercial sex workers and to $57 \%$ within 12 years in clients. The overall male and female prevalences reach $7 \%$. It then takes a $70 \%$ increase in condom use under SIDAl/2 to bring HIV prevalence down to $60 \%$ in commercial sex workers, and to 35\% in clients in 1996. While we may have overestimated the baseline level of condom use, it seems unlikely that transmission probabilities are twice the values assumed in the presence of condom use. The spread of HIV in the core groups would be too fast, given our strong assortative mixing. Since the amount of condom use at baseline is not considered to be part of the intervention, the estimates of the effectiveness of SIDAl/2 remain conservative.

\section{The STD modelled}

Gonorrhoea was the most prevalent STD in the commercial sex worker population. However, chlamydia and syphilis are reported more often among the general population. To assess the impact of this omission, the duration of gonorrhoea infection is increased to one year in the low risk groups only. The overall female and male gonorrhoea prevalence reaches $12 \%$ and $10 \%$ in 1998, respectively. Given a 10 -fold increase in STD rates, the impact on HIV is modest (twofold). The overall female and male HIV prevalence is $5.0 \%$ and $4.5 \%$ in 1998 , with a peak of $6.2 \%$ and $4.9 \%$. Changes in STD rates in the high risk groups are more critical.

\section{Mixing and circumcision}

A less assortative mixing pattern than currently assumed helps the overall diffusion of HIV but it also slows the initial spread in high risk groups. The sharp initial rise in HIV among commercial sex workers, the low overall HIV prevalence, and the equal male to female ratio argue in favour of a more assortative mixing in Cotonou. We have assumed a twofold increase in male susceptibility to HIV associated with the lack of circumcision. Under our model assumptions, a weak assortative mixing or the absence of circumcision is not of itself sufficient to produce an HIV prevalence as high as that observed in Kisumu or Ndola. ${ }^{12} 1317$ The presence of both these factors does have that effect, however, and thus they seem to play an important role in the epidemiology of HIV in Cotonou. The mixing is a nuisance parameter that prevents us determining the role of other risk factors and needs to be estimated more accurately.

\section{Effectiveness of the different interventions}

Even an extra $20 \%$ increase in condom use between commercial sex workers and frequent clients over the baseline level successfully reduces peak HIV prevalence by nearly half, and new infections by more than $21 \%$ and $42 \%$ over one and 10 years, respectively, in the Cotonou scenario. This suggests that the preventive efforts initiated in 1993 by the SIDAl/2 project may have limited further the spread of HIV and STD in both high and low risk groups. However, if we take the effect of AIDS differential mortality and frailty on STD and HIV trends with time into account, could the natural course of infection rather than SIDAl/2 intervention be responsible for the decrease in HIV and STD in commercial sex workers in Cotonou? We do not think so. In all the simulations performed, the rapid (but not drastic) rise and the sudden reversal of HIV prevalence around 1993 in commercial sex workers could not be reproduced without intervention, even if the duration of HIV in phase 1 was shortened to two months and the transmission probabilities in the different phases were varied to try to fit the data. It should be stressed, however, that this possibility cannot be entirely ruled out without a proper sensitivity analysis. To get a clearer picture of the course of the HIV epidemic in Cotonou and the effect of frailty selection, more attention should be paid to the dynamics of the commercial sex worker population (the renewal process and so $\mathrm{on}^{45}$ ) involved in the maintenance of STDs. It is important to quantify and incorporate heterogeneity in sexual behaviour in high risk groups (for example, the mixing pattern, duration of relationships, number of contacts per relationship, and so on). A better characterisation of the low risk groups is also important-in particular, the extent of clandestine prostitution and practices, the real level of sexual activity and concurrent partnerships in men and women, and the mixing patterns between these types of partnerships. 
In our simulations, the effectiveness of the SIDAl/2 intervention (intervention B) was solely due to the use of condoms. Screening $50 \%$ of the commercial sex workers once a year was clearly not enough to have a significant impact. In fact it requires the monthly screening of $100 \%$ of commercial sex workers to approach the effectiveness of SIDAl/2 intervention (not shown). Our screening strategies may underestimate the maximum potential of a syndromic approach because only gonorrhoea is included in the model. However, given the relatively poor sensitivity and specificity of STD syndromic approach (especially in women), many of the cases discovered and treated in our model (true positives) would be missed in reality, and many false positives would be treated in the field. ${ }^{46}{ }^{53}$ Interventions based on condom use or coupled with STD management seem more appropriate and feasible than those focusing solely on STD management, which required a very large fraction of the population to be screened very often. The overall effectiveness of condom use in partnerships between clients and commercial sex workers or low risk women (C4) increased with delayed introduction in the Cotonou scenario and ranked the best in the high prevalence scenario. We may have overestimated the effectiveness of all interventions because we have not accounted for implementation delays, interruptions of services (owing to hiccups in funding, prevention fatigue, and so on), or variability in screening patterns. ${ }^{7}$ Nevertheless, the model predictions provide important insights on the extent of efforts required to achieve fixed levels of intensity.

The preventive efforts in Cotonou have been initiated relatively early in the epidemic. ${ }^{14}$ This may have contributed to its apparent success, but because the epidemic was spreading at a slower pace than in most places the intervention could be introduced when the epidemic was not mature. Because the spread of HIV is slow in Cotonou, the epidemic is relatively fragile and responded quite well to all the interventions tested in our model. As the reproductive rate of an infection decreases, the impact made by small changes in parameters (modest intensity intervention) increases. ${ }^{4}$ Early in an epidemic, HIV propagates mostly from and to the core group. Interventions targeted to those people who are the focal point of infection are very efficient at limiting further transmissions. Core group interventions benefit the core population mostly directly and the non-core population indirectly by limiting HIV prevalence and the likelihood of exposure to HIV. As HIV prevalence increases in core groups, HIV diffuses from the core group to the non-core population and thereafter transmissions also occur within the non-core population (especially in high endemic areas). So interventions targeting relationships that form a bridge between core and non-core populations, such as those between clients of commercial sex workers and low risk partners, need to supplement core group interventions if a rapid reduction in incidence is expected. When the overall HIV prevalence is very high, an even more general population approach may be required. This does not mean that core group interventions are useless in mature epidemics. Although this may not be sufficient in the short term, we do believe that the primary focus of interventions should be the core group, even in high prevalence epidemics. Intense core group interventions (in the strict mathematical sense) provide the long term solution to the problem, as in theory they can lead to the eradication of the disease (this may take many decades)-which non-core interventions cannot do because they have to provide protection for ever. However, until the full potential is felt, the general population needs to be protected to minimise the caseload. The situation is similar to a boat with a hole in the hull. We have two choices to prevent it sinking. To fix the hole or to bail out continuously. However, even if we mend the hole, a minimum amount of bailing is required before the hold is dry. This does not mean that during the transitory bailing period repairing the hole was useless. What is unclear, however, is whether the boat will stay afloat if the hole is only partly covered.
It has been found previously that the effectiveness (the relative reduction in incidence) of STD interventions declines as the HIV epidemic matures. ${ }^{810}$ Our results show that this decline occurs with any intervention, mostly because of an indirect effect through reduced exposure to HIV. The indirect effect is maximal at the beginning of the epidemic, when prevalence is low, and decreases as HIV prevalence increases. As HIV prevalence increases, the period of time over which a given reduction in incidence or prevalence can be expected to occur following prevention lengthens. The implication for evaluation is that we have to be more patient to ascertain the effectiveness of an intervention. While both short term and long term effectiveness is important, short term evaluations can be misleading. On the one hand, even if an intervention can lead to the eradication of an infection (for example, gonorrhoea-based interventions in the Cotonou scenario), its impact in the short term can be very modest and may falsely suggest that it is not working. On the other hand, if an intervention is introduced early in a population with a high reproductive potential (large $\mathrm{Ro}_{\text {нгі }}$ ) then it may be falsely interpreted as having the same benefit in the long term as in the short term.

\section{Conclusions}

The conclusions from our analysis and their implications are clear. In a setting like Cotonou, all the conditions seem to have favoured a successful intervention. Even if SIDAl/2 intervention were successful, it would have been more so if introduced earlier. Above all, the success of an intervention mostly depends on the definition of success. What are the short term and long term objectives that we hope to achieve? Depending on that definition, Cotonou may have to improve its strategy. A realistic increase in intensity of core group interventions is expected to produce a further reduction in incidence and prevalence in both the high and the low risk groups. The current screening options in SIDAl/2 are clearly not enough. STD based interventions need to be intensified, whether or not the persistence of HIV really depends on STDs (assuming an enhancing effect of STDs on HIV). In Cotonou, the spread of both HIV and STD seems so intrinsically linked to the commercial sex workers and their frequent clients (acting as core groups) that sufficient STD screening in these groups can only help. Owing to some uncertainties in model predictions, it would be wise also to target partnerships between clients and low risk women before more intense core group interventions can be implemented or become fully effective. For an interesting discussion on the dynamics of HIV transmission in Cotonou, based on a detailed analysis of the epidemiological data, see the paper by Lowndes et al in this issue. ${ }^{14}$

Fast spreading or high prevalence epidemics reduce our window of opportunity for prevention. Core groups interventions are crucial but soon become insufficient. It becomes most important to target commercial sex workers and their clients as early as possible before the infection diffuses widely in the general population. In high endemic settings, one difficulty may be to ascertain which individuals really form the core group. In our Cotonou scenario, the core group seems to be formed by the commercial sex workers and their clients. It may include a larger fraction of the population in settings where HIV transmission probabilities are higher-owing to lack of circumcision, for example. Successful interventions require a more aggressive approach, earlier introduction, and higher intensity; therefore more money is needed to achieve the same effectiveness within a given time frame than in slower epidemics. Our results confirm those of early HIV models. ${ }^{5}$ Prevention is a long term commitment of sustained public health efforts that should be planned on a short and long term basis. Intensity and sustainability are the key to effective prevention strategies.

If HIV in Cotonou is progressing as slowly as it appears, it can be used as a natural laboratory to test and evaluate interventions, because we are more likely to observe an impact 
than in most places. This raises the crucial question of evaluating interventions. In theory, one wants to compare the intervention group with a control group. However, in practice this is rarely possible. Even with control populations, the experience of Rakai ${ }^{54}$ and Mwanza ${ }^{55}$ shows that the problem is not trivial. Cross sectional comparisons between populations with different size epidemics are also problematic. Comparisons of risk factors at a fixed time point may be blurred because of population changes (in rates of partner acquisition, network structure, size of core groups, STD rates, and so on) induced by the AIDS epidemic; over time these may, in some instances, be as large as the initial differences between populations. As seen in our Cotonou example, serial prevalence (or incidence data) over time cannot on their own be used to ascertain the effectiveness of an intervention. A decline in HIV incidence or prevalence can be observed even without any intervention, and no decrease in incidence or prevalence can be seen following an intervention. Furthermore, for a fixed intensity it takes longer to observe a general impact in a high prevalence scenario. When supported by sufficient behavioural and surveillance data, mathematical models can not only be useful in the planning of interventions but also in their evaluation. Our results show that the epidemic phases not only affect transmission and prevention but also the evaluation of interventions.

\section{ACKNOWLEDGMENTS}

We wish to thank Anne Buvé for giving us access to the unpublished results of the four cities study in sub-Saharan Africa. These results were first presented at the 7th Conference on Retroviruses and Opportunistic Infections, San Francisco. ${ }^{12}$ Many papers describe the various aspects of the study. ${ }^{13}$ We also acknowledge the work of $S$ Anagonou, M Laourou, and L Kanhounou in Benin, who were involved in the data collection and initial analysis. This work has been done in collaboration with the Centre de Coopération Internationale en Santé et Développement (CCISD).

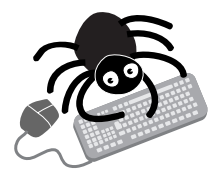

Appendix available on the website.

\section{Authors' affiliations}

M-C Boily, Centers for Disease Control and Prevention, National Center for HIV, STD, and TB Prevention, Atlanta, Georgia, USA

C Lowndes, M Alary, Groupe de recherche en épidémiologie de

I'Université Laval, Hôpital du Saint-Sacrement du CHA, Quebec, Canada

\section{REFERENCES}

1 Hetcothe HW, Yorke JA. Gonorrhea transmission dynamics and control. Lecture Notes Biomath 1984;56:103.

2 Anderson RM, May R. Infectious diseases of humans: dynamics and control. Oxford: Oxford University Press, 1991:757.

3 Kretzschmar M, van Duynhoven YT, Severijnen AJ. Modeling prevention strategies for gonorrhea and chlamydia using stochastic network simulations. Am J Epidemiol 1996;144:306-17.

4 Garnett GP, Anderson RM. Strategies for limiting the spread of HIV in developing countries: conclusions based on studies of the transmission dynamics of the virus. J Acquir Immun Defic Syndr Retrovirol 1995;9:500-13

5 Boily MC. Mathematical models of HIV-1 transmission in sub-Saharan Africa. London: University of London, 1992. [PhD thesis].

6 Boily MC, Lowndes C, Alary M, et al. Complementary hypotheses concerning the community STD mass treatment puzzle in Rakai, Uganda. AIDS 2000;27:558-71

7 Garnett GP, Bowden FJ. Epidemiology and control and curable sexually transmitted diseases: opportunities and problems. Sex Transm Dis 2000;27:588-99.

8 Robinson NJ, Mulder DW, Auvert B, et al. Proportion of HIV infections attributable to other sexually transmitted diseases in a rural Ugandan population: simulation model estimates. Int J Epidemiol 1997;26:180-9

9 Robinson NJ, Mulder DW, Auvert B, et al. Type of partnership and heterosexual spread of HIV infection in rural Uganda: results from simulation modeling. Int J STD AIDS 1999;10:718-25.
10 Boily M-C. Comparative study of the impact of non-ulcerative STD on HIV transmission in urban population of Africa and the USA. 11th Meeting of the International Society for STD Research (ISSTDR), New Orleans, Louisiana, 1995. [Abstract No 053.]

11 Wasserheit JN, Aral SO. The dynamic topology of sexually transmitted disease epidemics: implications for prevention strategies. J Infect Dis 1996; 174(suppl 2):S201-13.

12 Buvé A. HIV/AIDS in Africa: why so severe, why so heterogeneous? 7th Conference on Retroviruses and Opportunistic Infections, San Francisco, 30 Jan-2 Feb 2000.

13 The Study Group on Heterogeneity of HIV Epidemics in African Cities. The multicentre study on factors determining the differential spread of HIV in four African towns: summary and conclusions. AIDS 2001;15(suppl 4):S5-131

14 Lowndes C, Alary M, Meda $\mathrm{H}$, et al. Role of core and bridging groups in the transmission dynamics of HIV and STIs in Cotonou, Benin, West Africa. Sex Transm Infects 2002;78(suppl):i69-78.

15 Alary M. Impact of condom promotion and STD control on HIV and STD prevalence in female prostitutes in Cotonou, Benin: observation from the field in the context of a changing prostitution milieu. Durban, South Africa: 13th World AIDS conference, 9-14 July 2000.

16 Lowndes C, Alary M, Gnintoungbe CA, et al. Management of sexually transmitted diseases and HIV prevention in men at high risk: targeting clients and non-paying sexual partners of female sex workers in Benin. AIDS 2000;14:2523-34.

17 Morison L, Weiss H, Buvé A. Commercial sex work and the spread of HIV epidemics in four cities in Sub-Saharan Africa. AIDS 2001;15/suppl 4):S61-9

18 Aral SO, Roegner R. Mathematical modeling as a tool in STD prevention and control: a decade of progress, a millennium of opportunities. Sex Transm Dis 2000;27:556-7.

19 Soudeys H, Mukenge-Tshibaka L, Anagonou S, et al. Primo-infection au VIH: Les jeux sont ils deja faits? Medecine/Sciences 1996;suppl 2:9-16.

20 Royce RA. Sexual transmission of HIV. N Engl J Med 1997;336:10728.

21 Fauci AS, Pantaleo G, Stanley S, et al. Immunopathogenic mechanisms of HIV infection. Ann Intern Med 1996; 124:654-63.

22 Henrard DR, et al. Natural history of HIV-1 cell-free viremia. JAMA 1995:274:554-8

23 De Vincenzi I. A longitudinal study of human immunodeficiency virus transmission by heterosexual partners. N Engl J Med 1994;331:341-6.

24 Downs AM, de Vincenzi I. Probability of heterosexual transmission of HIV: Relationship to the number of unprotected sexual contacts. J Acquir Immune Defic Syndr Hum Retrovirol 1996;1 1:388-95

25 Mastro TD, de Vincenzi I. Probabilities of sexual HIV-1 transmission. AIDS 1996;10(suppl A):S75-82.

26 Shiboski SC, Padian NS. Epidemiological evidence for the time variation in HIV infectivity. J Acq Immun Defic Syndr Hum Retrovirol 1998; 19:527-35.

27 Quinn TC, Wawer M, Sewankambo N, et al. Viral load and heterosexual transmission of human immunodeficiency virus type 1. Rakai Project Study Group. N Engl J Med 2000;342:921-9.

28 Mastro TD, Satten GA, Nopkesorn T, et al. Probability of female-to-male transmission of HIV-1 in Thailand. Lancet 1994;343:204-7.

29 Kelly R, Kiwanaku N, Wawer NJ, et al. Age of male circumcision and risk of prevalent HIV infection in rural Uganda. AIDS 1999;13:399-405.

30 Bailey RC. A study in rural Uganda of heterosexual transmission of human immunodeficiency virus. N Engl J Med 2000;343:364-5.

31 Szabo R. How does male circumcision protect against HIV infection? BM 2000;320:1592-4.

32 Weiss HA, Quigley MA, Hayes RJ. Male circumcision and risk of HIV infection in sub-Saharan Africa: a systematic review and meta-analysis. AIDS 2000;14:2361-70.

33 Moses S, Nagelkerke NJ, Blanchard J, et al. Analysis of the scientific literature on male circumcision and risk for HIV infection. Int J STD AIDS $1999 ; 10: 626-8$

34 Cook LS, Koutsy LA, Holmes KK, et al. Circumcision and sexually transmitted diseases. Am J Public Health 1994;84:197-9.

35 Boily MC, Anderson RM. Human immunodeficiency virus transmission and the role of other sexually transmitted diseases. Measures of association and study design. Sex Transm Dis 1996;23:312-32.

36 Laga M, Alary M, Nzila N, et al. Condom promotion, sexually transmitted diseases treatment, and declining incidence of $\mathrm{HI}-1$ infection in female Zairian sex workers. Lancet 1994;344:246-8.

37 Brunham RC, Garnett GP, Swinton J, et al. Gonococcal infection and human fertility in sub-Saharan Africa. Proc R Soc Lond B Biol Sci 1991;246:173-7.

38 Garnett GP, Mertz KJ, Finelli L, et al. The transmission dynamics of gonorrhoea: modeling the reported behaviour of infected patients from Newark, New Jersey. Philos Trans R Soc Lond B Biol Sci 1999;354:787-97

39 Felton WF. Contrasting view on the infectivity of gonorrhoea. $\mathrm{Br} J$ Vener Dis 1973;49:151-4.

40 Holmes KK, Johnson DN, Trostle HJ, et al. An estimate of the risk of men acquiring gonorrhea by sexual contact with infected females. Am J Epidemiol 1970;91:170-4.

41 Hooper RR, Reynolds G, Jones OG, et al. Cohort study of veneral disease. I. The risk of gonorrhea transmission from infected women to men. Am J Epidemiol 1970;108: 136-40.

42 WHO/UNAIDS. Epidemiological fact sheet on HIV/AIDS and sexually transmitted diseases: Benin, June 1998. 
43 UNICEF. Enfants et femmes, avenir du Benin, 2nd ed. Cotonou, Bénin: Ministère du plan et, de la Restructuration Économique et de la Promotion de l'Emploi

44 Ministere du Plan-Ministere de la Sante-Ministere de I'education nationale. UNICEF/PNUD/FNUAP/WHO. Le Benin en chiffres. Cotonou, Bénin.

45 Alary M, Mukenge-Tshibaka L, Bernier F, et al. Decline in the prevalence of HIV and sexually transmitted diseases among female sex workers in Cotonou, Benin, 1993-1999. Aids (in press).

46 Germain M, Alary M, Guedeme A, et al. Evaluation of a screening algorithm for the analysis of genital infections with Neisseria gonorrhoea and Chlamydia trachomatis among female sex workers in Benin. Sex Transm Dis 1997;24:109-15.

47 Gregson S, Garnett GP. Contrasting gender differentials in HIV-1 prevalence and associated mortality increase in eastern and southern Africa: artefact of data or natural course of epidemics? AIDS 2000;14(suppl 3):S85-99.

48 Blower SM, van Griensven GJ. Effect of differential mortality on risk behavior change in cohort studies. J Acquir Immune Defic Syndr 1993;6: 1364-7
49 Boily MC, Anderson RM. Sexual contact patterns between men and women and the spread of HIV-1 in urban centres in Africa. IMA J Math Appl Med Biol 1991;8:221-47.

50 Korenromp EL, Bakker R, Gray R, et al. The effect of HIV, behavioural change, and STD syndromic management on STD epidemiology in sub-Saharan Africa: - simulations of Uganda. Sex Transm Infect 2002;78(suppl 1);i55-63.

51 Boily M-C, Masse RB, Desai KN (2001) The impact of antiretroviral therapy on STD trends with time. ISTTDR 24-27 June. Int J STD AIDS 2001;12(suppl 2):158.

52 Kretzschmar M Morris M. Measures of concurrency in networks and the spread of infectious disease. Math Biosci 1996;133:165-95.

53 Pettifor A, Walsh J, Wilkins V et al. How effective is syndromic management of STDs? A review of current studies. Sex Transm Dis 2000;27:371-85

54 Wawer MJ, Sewankambo NK, Serwadda P, et al. Control of sexually transmitted diseases for AIDS prevention in Uganda: a randomised community trial. Rakai Project Study Group. Lancet 1999:353:525-35.

55 Grosskurth H, Mosha F, Todd J. Impact of improved treatment of sexually transmitted diseases on HIV infection in rural Tanzania: randomised controlled trial. Lancet 1995;346:530-6.

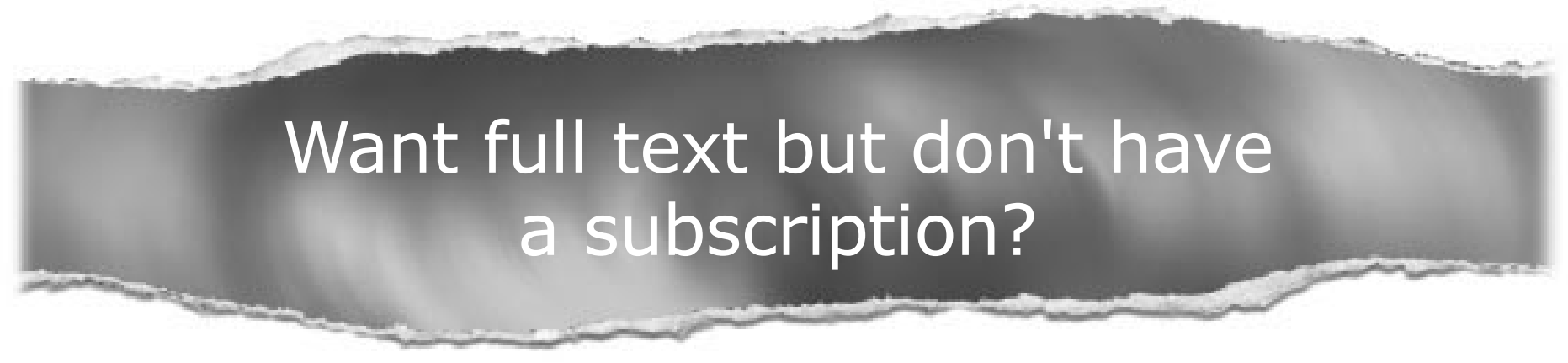

Pay per view

For just $\$ 8$ you can purchase the full text of individual articles using our secure online ordering service. You will have access to the full text of the relevant article for 48 hours during which time you may download and print the pdf file for personal use.

\section{www.sextransinf.com}

